Tohoku J. Exp. Med., 2009, 219, 53-62

\title{
Chinese Herbal Medicine Yi-Gan-San Decreases the Lipid Accumulation in Mouse 3T3-L1 Adipocytes by Modulating the Activities of Transcription Factors SREBP-1c and FoxO1
}

\author{
Masayuki Izumi, ${ }^{1,2}$ Takashi Seki, ${ }^{2}$ Koh Iwasaki ${ }^{2}$ and Kazuichi Sakamoto ${ }^{1}$ \\ ${ }^{1}$ Graduate school of Life and Environmental Sciences, University of Tsukuba, Ibaraki, Japan \\ ${ }^{2}$ Center for Asian Traditional Medicine, Graduate School of Medicine, Tohoku University, Miyagi, Japan
}

\begin{abstract}
Abnormal lipid metabolism in adipose tissue is closely related to the occurrence and progression of a wide variety of metabolic syndromes. We have analyzed the pharmacological effects of Chinese herbal medicines on cell differentiation and lipid metabolism in adipocytes. Yi-Gan-San (YGS) is a Chinese herbal medicine that is effective in treating the behavioral and psychological symptoms of dementia; however, its physiological mechanism remains unclear. We analyzed the effects of YGS on lipid accumulation in mouse 3T3-L1 adipocytes. Adipocyte differentiation was induced in mouse 3T3-L1 preadipocytes by treatment with the mixture of dexamethasone, 3-iso-butyl-1-methylxanthine, and insulin, and cells were cultured for 8 days with Chinese herbal medicines, including YGS. YGS effectively reduced the lipid accumulation in the differentiated 3T3-L1 cells in a dose-dependent manner, but had no effect on cell viability. YGS also reduced the activity of glycerol-3-phosphate dehydrogenase, an enzyme involved in lipid synthesis. In contrast, YGS gave no noticeable effect on glucose uptake and fatty acid uptake in the differentiated 3T3-L1 cells. Moreover, we established the stably transfected 3T3-L1 cell lines, each of which expresses the luciferase reporter gene under the control of sterol regulatory element-binding protein-1c (SREBP-1c) or FoxO1. SREBP-1c is a transcription factor involved in fatty acid synthesis, and FoxO1 is a forkhead-type transcription factor involved in adipocyte differentiation. Using these cell lines, we showed that YGS reduced the transcriptional activity of SREBP-1c, whereas YGS increased the activity of FoxO1. Thus, YGS may suppress lipid synthesis and fat accumulation in adipocytes through modulating the activities of SREBP-1c and FoxO1. — Yi-Gan-San; SREBP-1c; FoxO; Adipocyte; 3T3-L1.
\end{abstract}

Tohoku J. Exp. Med., 2009, 219 (1), 53-62. 두 2009 Tohoku University Medical Press

The abnormal lipid metabolism in adipose tissue is strongly associated with the occurrence and progression of metabolic syndromes (MS), including Diabetes mellitus (DM) (Shah et al. 2008; Kamada et al. 2008; Eckardt et al. 2008). Recently, it was reported that a disorder of lipid metabolism is also involved in aggravating of Alzheimer's disease (AD) (Ott et al. 1999; Kivipelto et al. 2005; Luchsinger and Mayeux 2007). On the other hand, the adipocyte secretes bioactive substances and growth factors, under the control of other organs, and plays an important role as an internal secretion cell for the homeostasis maintenance of the living body (Wozniak et al. 2009; Rasouli and Kern 2008). Therefore, analysis of lipid metabolism and adipocytokine-related gene expression in adipocytes is critical to the basic research for the prevention and treatment of these diseases.

A transcription factor, sterol regulatory element-binding protein-1c (SREBP-1c), is enriched in the liver and adipocyte, and it is involved in the synthesis of fatty acids and cholesterol and is a main regulator of lipid metabolism under the control of the insulin signal cascade (Yang et al. 2007). Three isoforms, SREBP-1a, SREBP-1c, and SREBP-2, form the SREBP family (Eberlé et al. 2004). SREBP-1c has also been associated with the occurrence of DM, obesity and AD (Kotzka and Müller-Wieland 2004; Kelicen and Nordberg 2006; Bonzón-Kulichenko et al. 2009). In patients with lipid metabolic disorder, Reactive Oxygen Species (ROS) level in the blood is a little higher than normal people (Mecocci et al. 2002; Potenza et al. 2009). We have reported that ROS promotes lipid accumulation through the activation of SREBP-1c (Sekiya et al. 2008). Therefore, we focused on SREBP-1c as a key factor for understanding the mechanism of lipid metabolic disease. We also focused on FoxO (Forkhead box class O), the forkhead-type transcription factor that promotes the expression of superoxide dismutase (SOD), catalase and other cell-survival related genes, which are part of the insulin-signaling cascade (Kops et al. 2002; Curtis et al. 2007; Erol 2009).

Received July 3, 2009; revision accepted for publication July 27, 2009. doi:10.1620/tjem.219.53

Correspondence: Kazuichi Sakamoto, Graduate school of Life and Environmental Sciences, University of Tsukuba, Ibaraki, 305-8572 Japan.

e-mail: sakamoto@biol.tsukuba.ac.jp 
Chinese herbal medicines are effective against various diseases, such as dementia, pneumonia, and arteriosclerosis, and have few side effects (Iwasaki et al. 2004, 2007; Zhang et al. 2008). In particular, Yi-Gan-San (YGS, Japanese name: Yokukansan) has been used to treat neurosis and insomnia (Miyaoka et al. 2008). Recently, it was reported that YGS is effective against the behavioral and psychological symptoms of dementia (BPSD) (Iwasaki et al. 2005; Mizukami et al. 2008). Although psychoactive drugs and antipsychotics are commonly used for the treatment of BPSD, antipsychotics possibly increase the risk of death among the elderly (Wang et al. 2005), and increase body weight and insulin resistance (Nasrallah 2003; MinetRinguet et al. 2006) as side effects. Compared to these medicines, Chinese herbal medicines generally have lesser side effects. Among them, YGS is particularly effective for cell protection and maintenance of cellular function (Tateno et al. 2008; Egashira et al. 2008). So far, there is no report that YGS is involved in the aggravation of lipid metabolism. Though the clinical effect of Chinese herbal medicine is obvious, the pharmacological effect to the cultured cell and its molecular mechanism are little known.

To understand the role of YGS in lipid metabolism, we analyzed the pharmacological effects of lipid accumulation and biochemical effects to transcription factor SREBP-1c by using mouse 3T3-L1 preadipocytes. Rikkunshito (RST) (Takeda et al. 2008) and Hochuekkito (HET) (Matsumoto et al. 2007), which have different effect to YGS, were used as comparative medicines.

\section{Materials and Methods}

Cell culture

3T3-L1 cell line was obtained from the Health Science Research Resources Bank (HSRRB, Osaka, Japan). Cells were cultured in Dulbecco's modified Eagle's medium (DMEM High-glucose) (SigmaAldrich, St. Louis, MO, USA) supplemented with 10\% FBS (Sanko Junyaku, Tokyo, Japan). Cells were cultured for 2 days to confluence then for a further 2 days in media supplemented with $0.25 \mathrm{mM}$ dexamethasone (Sigma-Aldrich), $0.5 \mathrm{mM}$ 3-iso-butyl-1-methylxanthine (Sigma-Aldrich), and $10 \mu \mathrm{g} / \mathrm{ml}$ insulin (Wako, Osaka, Japan) (DMI induction). Then, cells were cultured for 2 days in media containing 5 $\mu \mathrm{g} / \mathrm{ml}$ insulin, and for 4 days in standard culture media.

\section{Chinese herbal medicine}

Yi-Gan-San (YGS) (TJ-54. Tsumura, Tokyo, Japan), Rikkunshito (TJ-43. Tsumura) and Hochuekkito (TJ-41. Tsumura) were kindly provided from Tsumura Co. Ltd. Five grams of these powders were dissolved in $50 \mathrm{ml}$ double distilled water, autoclaved and centrifuged at $12,000 \times \mathrm{G}$ for $20 \mathrm{~min}$ (RS-2IV. TOMY SEIKO, Tokyo, Japan). The supernatant was filter-sterilized $(20 \mu \mathrm{m}$. Sartorius, Göttingen, Germany).

\section{Oil-Red-O staining}

To know the effect of YGS on lipid accumulation, we performed Oil-Red-O stain analysis. After washing cells with PBS, cells were fixed with $4 \%$ paraformaldehyde (Kantou Chemistry, Tokyo, Japan) for $1 \mathrm{~h}$ and then stained with $3 \mathrm{mg} / \mathrm{ml}$ Oil-red-O (in 60\% isopropanol) for $10 \mathrm{~min}$. Cells were washed with sterile water then observed under a microscope (DMIRBE M2FLIII, Leica Microsystems Inc., Bannockburn, IL, USA). In addition, cells were stained with $0.3 \mathrm{mg} /$ $\mathrm{ml}$ Oil-red-O, and the dye was eluted for $10 \mathrm{~min}$ with $100 \%$ isopropanol. The absorbance (O.D. $420 \mathrm{~nm}$ ) was measured by a DU640 Spectrophotometer (Beckman, California, USA).

\section{MTT assay}

To know the effect of YGS on cell viability, we performed the MTT analysis. 3T3-L1 cells were plated on a 96-well plate at $1 \times 10^{4}$ cells/well and cultured for 4 days. Immediately after DMI induction, cells were cultured with $1,000 \mu \mathrm{g} / \mathrm{ml}$ of YGS for an additional 8 days. After the culture, cells were washed with PBS, and incubated with $250 \mu \mathrm{g} / \mathrm{ml}$ MTT solution (5 mg Thiazolyl Blue Teyrazolim Bromide, Sigma-Aldrich) for an additional $4 \mathrm{~h}$. The product was dissolved in $0.04 \mathrm{~N} \mathrm{HCl}$ in isopropanol, and the absorbance at $570 \mathrm{~nm}$ was measured.

\section{Trypan Blue staining}

To know the effect of YGS on cell viability, we performed the Trypan Blue analysis. 3T3-L1 cells were plated on 60-mm plates at 3 $\times 10^{5}$ cells/well and cultured for 4 days. Immediately after DMI induction, cells were cultured with $1,000 \mu \mathrm{g} / \mathrm{ml}$ of YGS for an additional 8 days. After the culture, cells were washed with PBS, and then incubated with $1 \mathrm{ml}$ of $0.5 \times$ trypan blue solution (Trypan Blue, Sigma-Aldrich) for $1 \mathrm{~min}$. Cells were washed with PBS and observed under an optical microscope. Cell viability was calculated by the number of living cell and dead cell.

\section{Glucose transport}

To know the effect of YGS on glucose transport, we performed Glucose uptake analysis. The cells were cultured with YGS for 8 days, and then treated with $10 \mathrm{ml} \mathrm{KRP-H}$ buffer $(131.2 \mathrm{mM} \mathrm{NaCl}, 4.7$ $\mathrm{mM} \mathrm{KCl}, 2.5 \mathrm{mM} \mathrm{NaH}_{2} \mathrm{PO}_{4}, 2.5 \mathrm{mM} \mathrm{CaCl}_{2}, 1 \mathrm{mM} \mathrm{MgSO}{ }_{4}, 1 \mathrm{mM}$ HEPES (pH 7.4) containing $10 \mathrm{mM}$ 2-NBDG (2-(N-(7-nitrobenz-2oxa-1, 3-diazol-4-yl)amino)-2-deoxyglucose) (Invitrogen Life Technologies, Carlsbad, CA, USA) at $37^{\circ} \mathrm{C}$ for $10 \mathrm{~min}$. After washing the cells with KRP-H buffer, cells were observed under a LEITZ DMRXA HC RXA-6 fluorescence microscope (Leica, Solms, Germany).

\section{Fatty acid transport}

To know the effect of YGS on fatty acid transport, we performed Fatty acid uptake analysis. The cells were cultured with YGS for 8 days, and then treated with PBS $\left(\mathrm{Ca}^{2+} / \mathrm{Mg}^{2+}\right)$ containing $20 \mathrm{mM}$ BODIPY3823 (Invitrogen) and $20 \mathrm{mM}$ BSA (fatty acid free, Wako) at $37^{\circ} \mathrm{C}$ for $2 \mathrm{~min}$. After washing the cells twice with PBS containing 20 mM BSA, cells were observed under a LEITZ DMRXA HC RXA-6 fluorescence microscope (Leica).

\section{Glycerol-3-phosphate dehydrogenase activity}

To know the effect of YGS on lipid synthesis, activity of glycerol-3-phosphate dehydrogenase (GPDH), an enzyme involved in lipid synthesis, was analyzed. 3T3-L1 cells were plated on $60-\mathrm{mm}$ plates at $3 \times 10^{5}$ cells/well and cultured for 4 days. Immediately after DMI induction, cells were cultured with $1,000 \mu \mathrm{g} / \mathrm{ml}$ of YGS for an additional 8 days. Then cells were treated with GPDH buffer $(0.28 \mathrm{M}$ Sucrose 9.58g, 5 mM Tris-HCL $500 \mu 1,1$ mM EDTA $200 \mu 1$, dDW $99.1 \mathrm{ml}, 0.002 \% \beta$-ME $200 \mu \mathrm{l})$ and $10 \times$ protein inhibitor $(1 \mathrm{mM}$ 
AEBSF (SIGMA), $130 \mu \mathrm{M}$ Bestatin (Wako), $14 \mu \mathrm{M}$ E-64 (SIGMA)), $1 \mathrm{mM}$ EDTA (Wako, $1 \mu \mathrm{M}$ pepstatin A (SIGMA). After homogenization (0.5-Amplitude; 60$)$, cell lysates were centrifuged $(15,100 \times \mathrm{G}$, $\left.4^{\circ} \mathrm{C}, 10 \mathrm{~min}\right)$. The supernatant was mixed with GPDH reaction buffer
(TAE solution $5 \mu 1,5 \mathrm{mM}$ dehydroxy aceto phophatic acid $10 \mu 1,0.5$ mM NADH, dDW $51 \mu 1$ ), and O.D. (340 nm) was measured.

Table 1. Primers for RT-PCR. PCR was performed using the primers indicated below under optimal amplification conditions $\left(95^{\circ} \mathrm{C}\right.$ for $10 \mathrm{~min} ; 35-38$ cycles of $95^{\circ} \mathrm{C}$ for $30 \mathrm{sec}, 51-58^{\circ} \mathrm{C}$ for $30 \mathrm{sec}, 72^{\circ} \mathrm{C}$ for $30 \mathrm{sec} ; 72^{\circ} \mathrm{C}$ for $7 \mathrm{~min}$ ) for each gene. The PCR amplification of each cDNA was performed independently using three samples in triplicate.

\begin{tabular}{lll}
\hline \multicolumn{1}{c}{ Gene } & \multicolumn{1}{c}{ Sense } & \multicolumn{1}{c}{ Anti-sense } \\
\hline SREBP-1c & ACTTCTAGACGGGCGCCCATGGAGACT & ACTTCTAGATCCTCAAAGGCTGGA \\
PGC-1a & GCAGAAGAGCCGTCTCTA & CCTGCAGTTCCAGAGAGT \\
UCP2 & CCTGATTGCAGATCTCAA & AGGTCATAGGTCACCAGC \\
PPAR $\gamma$ & AATAGATCTTGATTAGGAGTTTCA & ATTAAGCTTACCATGCTCTGGGTC \\
Adiponectin & GGACATCCTGGCCACAAA & GTCCTTCTTGAAGAGGCT \\
Adipsin & CTGCTGGACGAGCAGTGG & GATGACACTCGGGTAT \\
CD36 & GCAGAAGAGCCGTCTCTA & AGGTCGATTCAGATCCGC \\
GLUT4a & TGCTGGGCACAGCTAGCTACC & TATGGCCACGATGGAGAC \\
C/EBP & CAGCGGCAGCCTGTCCAC & CACGTGTGTTGCGTAGTC \\
Foxo1 & GATCTACGAGTGGATGGT & CAGCGTAGACGCCATCTT \\
SIRT1 & TAATCAGGTAGTTCCTCG & AAAGTTTGGCATATTCAC \\
MnSOD & CCCATCTCCACTAAAAAT & CAGCCTCCCGAGTAGCTG \\
Cu/ZnSOD & TTAACTGAAACCAGCATC & CAGATGATGCTGAGACTC \\
Catalase & TTGGCCTCACAAGGACTA & GGCAATGTTCTCACACAG \\
$\beta$-actin & CCGGGACCTGACGGACTACCTCATGAAGAT & AATAGTGATGACTTGGCCGTCAGGCAGCTC \\
\hline
\end{tabular}

A

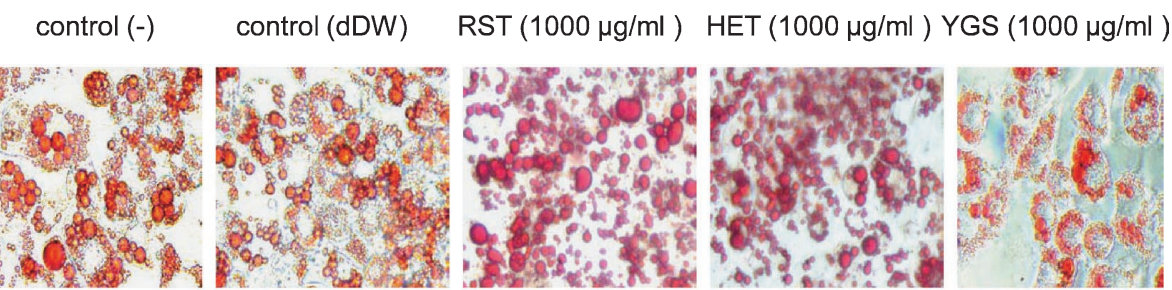

B

C
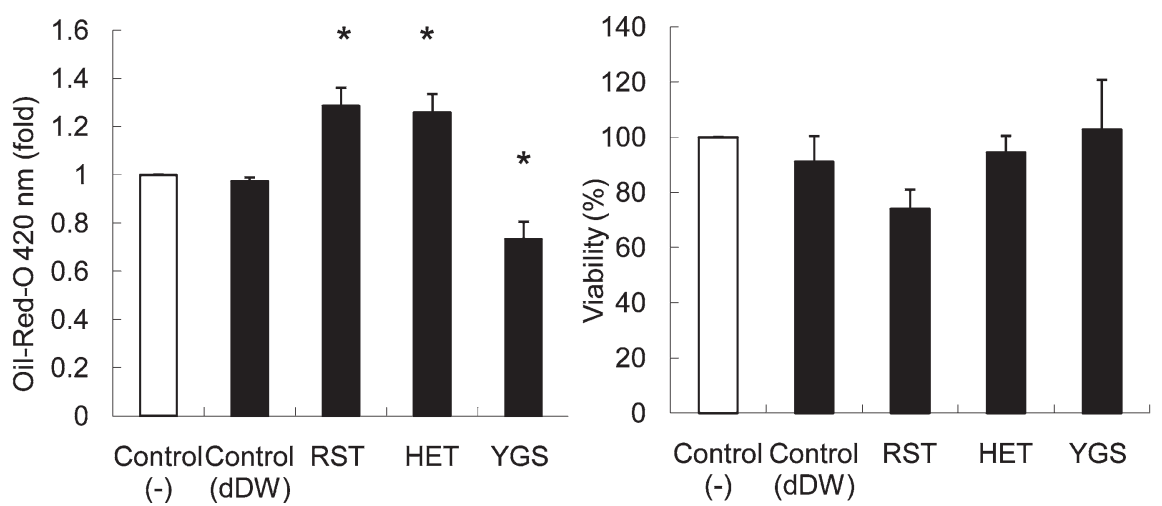

$(-) \quad(\mathrm{dDW})$

Fig. 1. Effect of Chinese herbal medicines on lipid accumulation. (A) 3T3-L1 cells were cultured in 48-well plates at $2 \times 10^{4}$ cells/well for 4 days. Differentiation was induced with DMI, and the cells were then immediately cultured with 1000 $\mu \mathrm{g} / \mathrm{ml}$ of YGS, RST, or HET for an additional 8 days. Untreated cells [control (-)] and double distilled water (1\%)-treated cells [control $(\mathrm{dDW})]$ were used as negative controls. Cells were stained with Oil-red-O to label lipids. (B) After Oil-red-O staining, the dye was eluted from the cells with isopropanol and quantified, and the results were plotted. $* P<0.05$, (C) 3T3-L1 cells were cultured in 96-well plates at $1 \times 10^{4}$ cells/well and treated with YGS, RST, or HET for 8 days. After the culture, cell viability was assessed with an MTT assay ( $n=3$ cultures/condition). 
Luciferase reporter assay

To know the effect of YGS on the activity of each transcription factors, we performed Luciferase reporter analysis. We prepared the DNA fragments that carry the consensus sequence (Insuline Responsive Sequence 3; IRS3) or the genomic sequence (catalase promoter region: Catalase) of FoxO binding site, and the consensus sequence (SREBP-1c Responsive Element: SRE) of SREBP-1c binding site. The luciferase reporter plasmids with a FoxO DNA-binding site (IRS3-Luc, Catalase-Luc) and with a SREBP-1c DNA-binding site (SRE-Luc) were constructed. The stable 3T3-L1 cells that carry IRS3-Luc, Catalase-Luc or SRE-Luc were established (3T3-L1/IRS3Luc, 3T3-L1/Catalase-Luc, 3T3-L1/SRE-Luc). The cells were cultured on $60-\mathrm{mm}$ plates at $3 \times 10^{5}$ cells/well. After 8 days culture with YGS, cells were incubated with $450 \mathrm{ml}$ Reportor Lysis Buffer (Promega, Madison, WI, USA) for $60 \mathrm{~min}$ at $-80^{\circ} \mathrm{C}$. After brief centrifugation $(32,000 \times \mathrm{G}, 3 \mathrm{~min})$ of the cell lysates, supernatant was collected and luciferase activity was measured with a Luminometer Micro Lumat LB96p (Berthold Technology, Germany), and plotted on a graph after normalization by cell number.

\section{$R T-P C R$}

To know the effect of YGS on gene expression, we performed
RT-PCR analysis. The cells were cultured with YGS for 8 days, and RNA was extracted by the standard GTC-acid phenol method (Chomczynski and Sacchi 1987). After cDNA synthesis with M-MLV reverse transcriptase (Takara, Shiga, Japan), PCR was performed with the primers indicated in Table 1. PCR $\left(95^{\circ} \mathrm{C}\right.$ for $10 \mathrm{~min} ; 35-38$ cycles of $95^{\circ} \mathrm{C}$ for $30 \mathrm{sec}, 51-58^{\circ} \mathrm{C}$ for $30 \mathrm{sec}, 72^{\circ} \mathrm{C}$ for $30 \mathrm{sec} ; 72^{\circ} \mathrm{C}$ for 7 min) was performed using TP600 (Takara).

\section{Statistical analysis}

Results are expressed was as mean \pm standard deviation. Comparisons between groups were made by analysis of variance (ANOVA), were examined by Tukey's all-pairwise-comparison test. Differences were considered significant when $P<0.05$. Statistical analysis was performed using Excel 2004 (Microsoft, Redmond, WA, USA) with the add-in software Statical (Kamon et al. 2008).

\section{Results}

\section{Effect of YGS on lipid accumulation}

Adipocyte differentiation was induced in mouse 3T3-L1 preadipocytes by DMI treatment. YGS was then added to the cells, which were cultured for a further 8 days. Because our preliminary experiments revealed that YGS
A

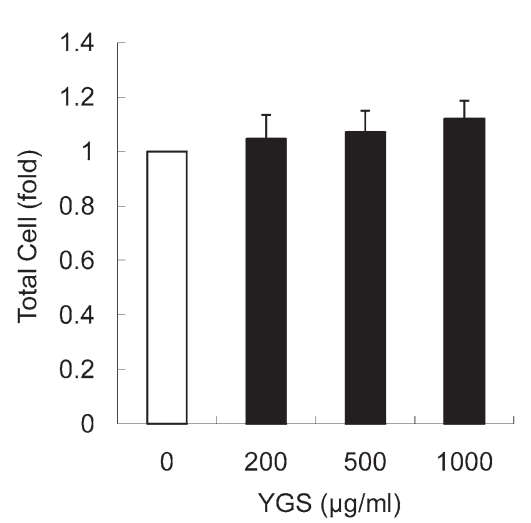

C

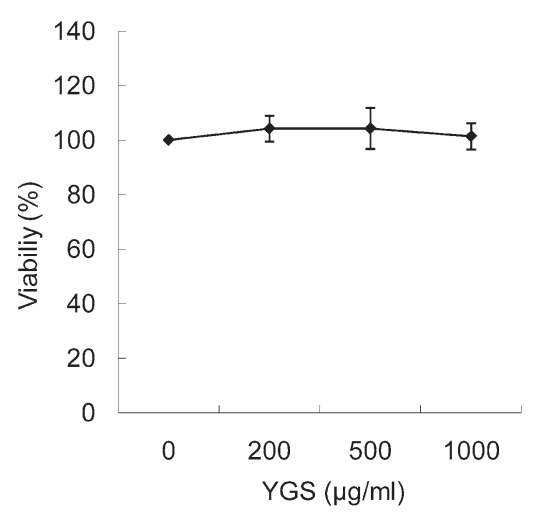

B

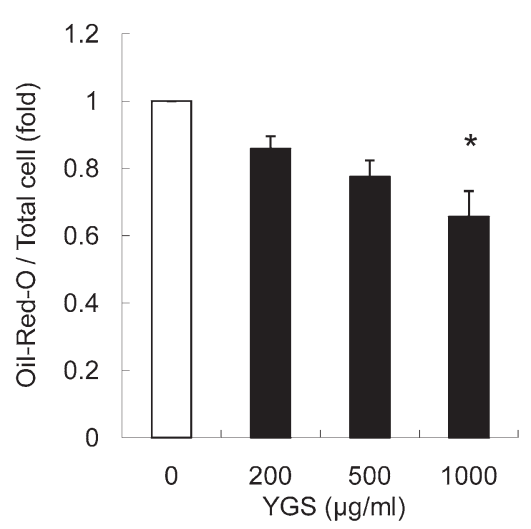

D

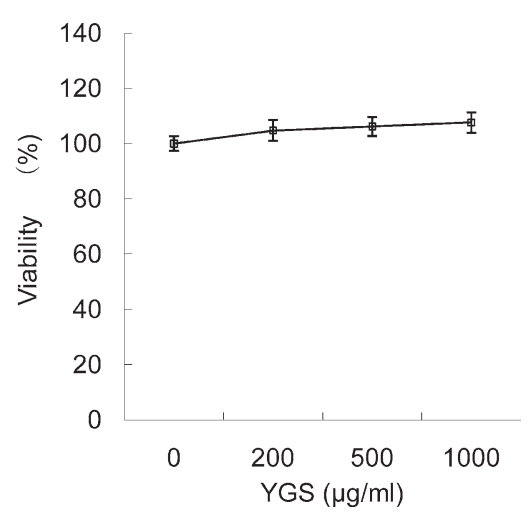

Fig. 2. Effect of YGS on lipid accumulation. 3T3-L1 cells were cultured for 4 days, induced with DMI, and cultured with YGS $(200,500$, or $1,000 \mu \mathrm{g} / \mathrm{ml})$ for an additional 8 days. (A) Cells were cultured with YGS on $60-\mathrm{mm}$ plates at $3 \times 10^{5}$ cells/plate, then counted ( $n=6$ cultures/condition). (B) After Oil-red-O staining, the dye was extracted and quantified with a spectrophotometer. $* P<0.05$ ( $n=9$ cultures/condition). (C) Cells were cultured in 96 -well plates at $1 \times 10^{4}$ cells/well and cell viability was analyzed with an MTT assay $(n=9$ cultures/condition). (D) Cells were cultured on 60 -mm plates at $3 \times 10^{4}$ cells/plate. After culture with the indicated concentration of YGS, dead cells were detected by Trypan Blue staining, and cell viability was plotted $(n=6)$. 
$(100,200,300,500,1,000,2,000 \mu \mathrm{g} / \mathrm{ml})$ gave little effects to cell viability, we applied a maximum $1,000 \mu \mathrm{g} / \mathrm{ml}$ of YGS, a dose which gave the most remarkable and reliable effects to lipid accumulation. We also applied $1,000 \mu \mathrm{g} / \mathrm{ml}$ of Rikkunshito (RST) and Hochyuekkito (HET) to parallel cell cultures as controls. The cells were then stained with Oil-red-O to assess lipid accumulation. YGS significantly reduced lipid accumulation relative to that in controls (Figs. 1A, B), whereas RST and HET increased lipid accumulation. The results of an MTT assay showed that YGS and HET had no effect on cell viability (Fig. 1C), whereas RST slightly decreased cell survival. After 8 days of treatment with 200,500 , or $1,000 \mu \mathrm{g} / \mathrm{ml} \mathrm{YGS}$, the total number of cells had not changed greatly (Fig. 2A), but YGS had reduced lipid accumulation in a dose-dependent manner (Fig. 2B). MTT and Trypan Blue staining assays confirmed that YGS had little effect on cell viability (Figs. 2C, D).

\section{Effect of YGS on lipid accumulation in differentiated adipocytes}

Eight days after DMI induction, we incubated 3T3-L1 cells with YGS for 2 days (days 8-10 after DMI treatment), 4 days (days 8-12), 6 days (days 8-14), or 8 days (days 8-16). YGS reduced lipid accumulation in differentiated adipocytes (Fig. 3A). Quantification of Oil-red-O in the cells confirmed that YGS treatment reduced lipid accumulation (Fig. 3B) without affecting cell viability (Fig. 3C).
Effect of YGS on GPDH activity and uptake of glucose and fatty acids

Immediately after DMI induction, we added 1000 $\mu \mathrm{g} / \mathrm{ml}$ YGS to the cell culture. To assess the incorporation of glucose and fatty acid after exposure to YGS, cells were treated with 2-NBDG or BODIPY3823. YGS had no effect on glucose uptake (Fig. 4A) or fatty acid uptake (Fig. 4B). Immediately after DMI induction, we added 1,000 $\mu \mathrm{g} / \mathrm{ml}$ YGS to the cell culture and analyzed the enzymatic activity of glycerol-3-phosphate dehydrogenase (GPDH). YGS significantly reduced GPDH activity (Fig. 4C).

\section{Effect of YGS on transcriptional activity of SREBP-1c} and FoxO

3T3-L1 cells were stably transfected by luciferase reporter plasmids carrying the FoxO (IRS3-Luc, CatalaseLuc) and SREBP-1c (SRE-Luc) DNA binding sites respectively. We treated these cells with 200,500 , or $1000 \mu \mathrm{g} / \mathrm{ml}$ YGS for 8 days and analyzed the luciferase activity. The luciferase reporter assay revealed the direct activity of transcription factor, which acts on the specific luciferase reporter plasmid, leading to the change of expression and resultant enzyme activity of luciferase. Transcriptional activity of SREBP-1c was decreased with increasing concentration of YGS (Fig. 5A), whereas transcriptional activity of FoxO was increased (Figs. 5B, C).

A

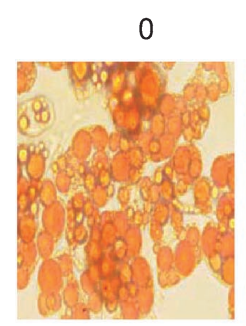

2

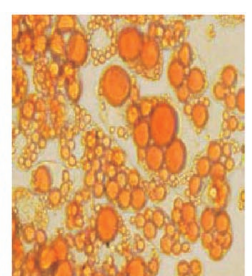

4

6
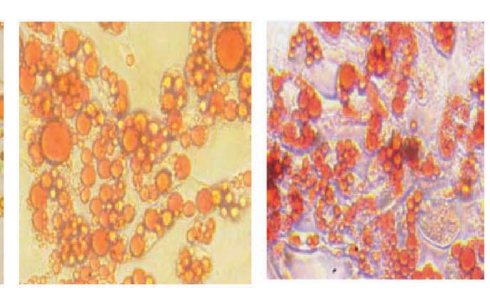

8 days

B

C
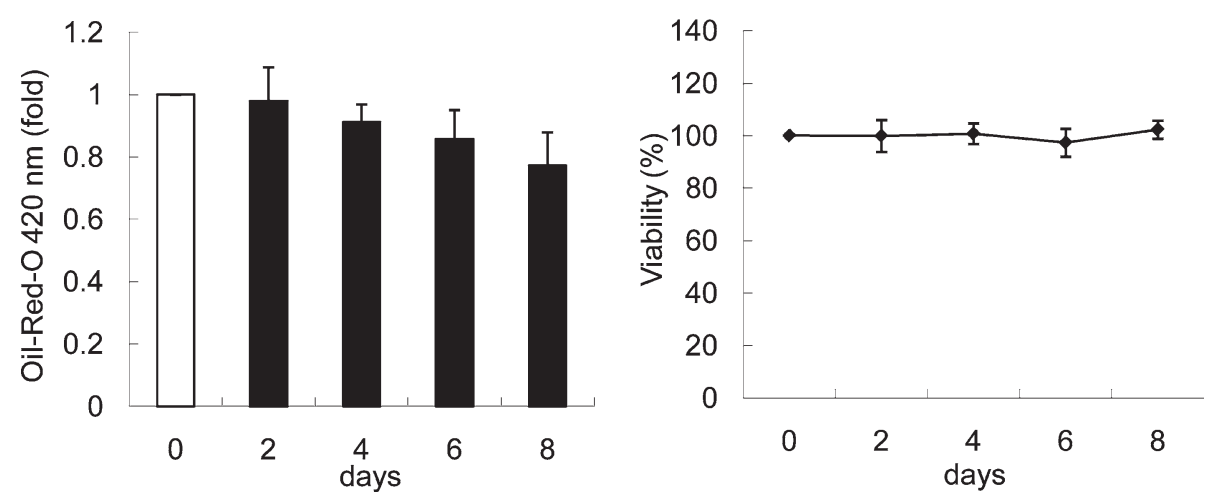

Fig. 3. Effect of YGS on lipid accumulation in differentiated adipocytes. 3T3-L1 cells were cultured for 4 days, treated with DMI, cultured for further 8 days, and then treated with YGS $(1,000 \mu \mathrm{g} / \mathrm{ml})$ for 2 days (days $8-10$ after DMI treatment), 4 days (days 8-12), 6 days (days 8-14), or 8 days (days 8-16). After Oil-red-O staining, (A) cells were observed with a microscope, and (B) the dye was eluted and quantified (O.D. $420 \mathrm{~nm})(n=9$ cultures/condition). (C) Cell viability was analyzed by MTT assay ( $n=9$ cultures/condition). 
A
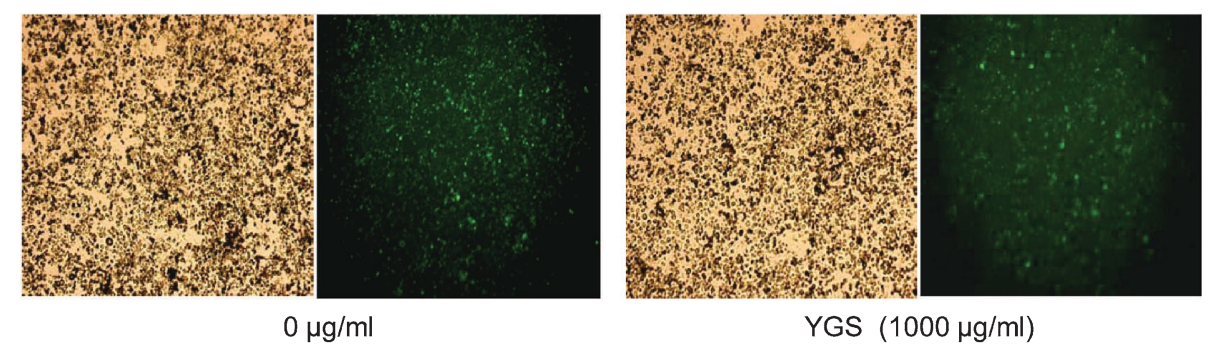

B

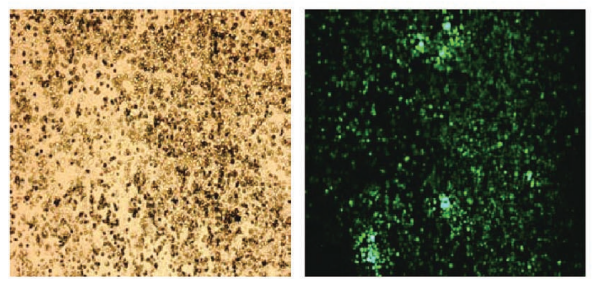

$0 \mu \mathrm{g} / \mathrm{ml}$

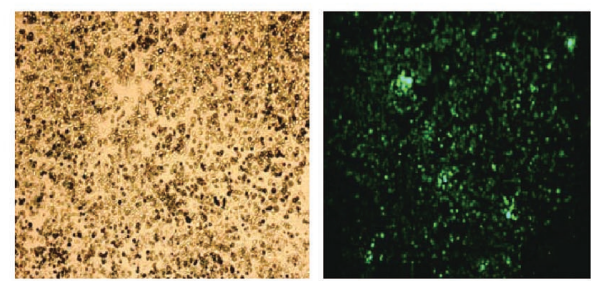

YGS $(1000 \mu \mathrm{g} / \mathrm{ml})$

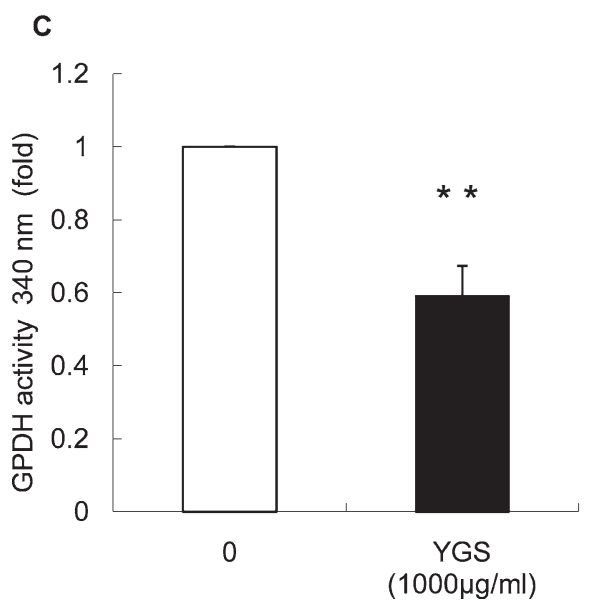

Fig. 4. Effect of YGS on GPDH activity and uptake of glucose and fatty acids. 3T3-L1 cells were cultured on 60-mm plates at $3 \times 10^{5}$ cells/plate for 4 days, induced to differentiate with DMI, and cultured with $1,000 \mu \mathrm{g} / \mathrm{ml}$ of YGS for an additional 8 days. To know the effect of YGS on glucose transport and fatty acid transport, cells were treated with $10 \mathrm{mM}$ 2-NBDG and $20 \mathrm{mM}$ BODIPY3823, respectively. After the culture with YGS, (A) glucose uptake and (B) fatty acid uptake were analyzed. (C) GPDH activity was analyzed in YGS-treated cells. $(* * P<0.01, n=3)$

\section{Effect of YGS on gene expression}

We next used RT-PCR to analyze gene expression in 3T3-L1 cells treated with 200, 500, or $1,000 \mu \mathrm{g} / \mathrm{ml}$ YGS. The mRNA level of SREBP-1c was substantially reduced (Fig. 6). Expression of the mRNAs of PGC-1 $\alpha$ (peroxisome proliferator-activated receptor $-\gamma$ coactivator- $\alpha$ ), UCP2 (uncoupling proteins-2) (Kakuma et al. 2000; Arumugam et al. 2008), PPAR- $\gamma$ (peroxisome proliferator-activated receptor- $\gamma$ ) (Tjokroprawiro 2006; Escribano et al. 2009), adiponectin (Migrenne et al. 2009), adipsin (Drevon 2005), FoxO1, SIRT1 (silent mating type information regulation 2 homolog) (Frescas et al. 2005), MnSOD, Cu/ZnSOD, and catalase (Tothova et al. 2007) increased, whereas expression of CD36 (Hickman et al. 2008), GLUT4 (glucose transporter 4) (Barros et al. 2008), and C/EBPs (CCAAT/enhancerbinding proteins) (Obregon 2008) did not change at all.

\section{Discussion}

We evaluated the pharmacological effects of a Chinese herbal medicine, YGS, on differentiation and adipogenesis of mouse 3T3-L1 preadipocytes. YGS reduced lipid accumulation in differentiated 3T3-L1 cells in a dose- and incubation period-dependent manner without affecting cell viability (Figs. 1, 2, 3). Because YGS also reduced the enzyme activity of GPDH (Fig. 4) and the gene expression and transcriptional activity of SREBP-1c (Figs. 5, 6), YGS likely reduced lipid accumulation by controlling lipid synthesis.

SREBP-1c is a key regulatory transcription factor that controls fatty acid synthesis under the regulation of the insulin signal cascade (Liu et al. 2008). SREBP-1c also increases insulin resistance in lipid metabolic diseases by suppressing insulin receptor substrate-2 (Shimano 2002). In addition to affecting the expression of SREBP-1c through 
A

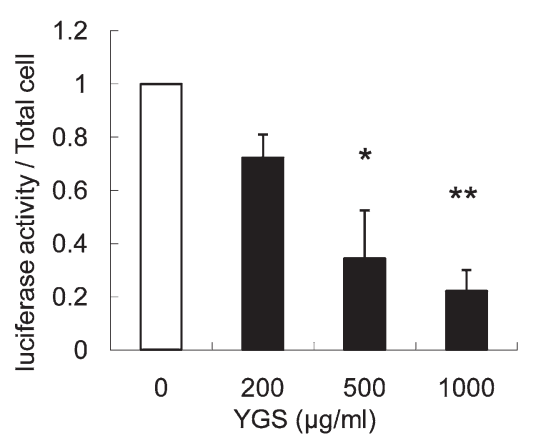

C

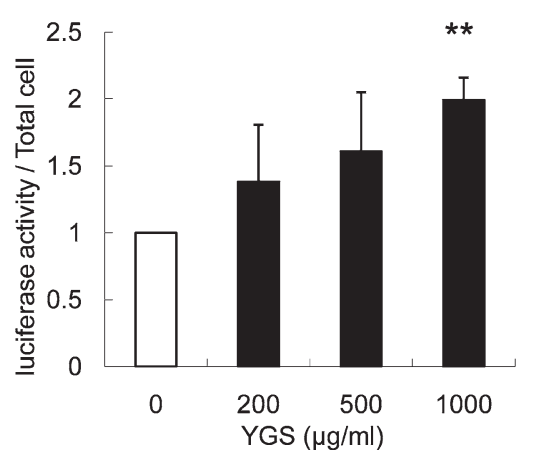

$c$
B

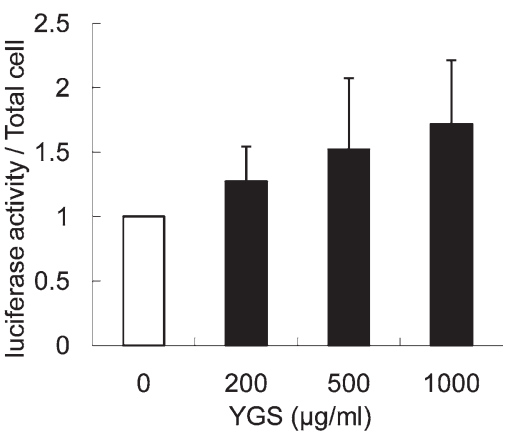


(Atractylodis Lanceae Rhizoma, Poria, Cnidii Rhizoma, Uncariae Uncis Cum Ramulus, Angelicae Radix, and Bupleuri Radix Glycyrrhizae Radix), of which Uncariae Uncis Cum Ramulus plays a role in cell survival through the activation of anti-oxidative enzymes (Mahakunakorn et al. 2005) and suppression of $\mathrm{A} \beta$ accumulation (Fujiwara et al. 2006). Our results indicated that YGS induces the expression of the genes encoding SOD and catalase (Fig. 5), which act as anti-oxidants. As it is known that FoxO family is involved in the regulation of expression of MnSOD and catalase (Olmos et al. 2009), our present data demonstrated the similar results (Fig. 4). Furthermore, we and other groups previously revealed that ROS promote lipid accumulation by stimulating SREBP-1c activity (Kohjima et al. 2007; Sekiya et al. 2008). These findings suggest that the anti-oxidative activity of YGS may have led to the suppression of SREBP-1c transcriptional activity. Recently, Wang et al. reported that resveratrol possibly attenuate fat deposition by inhibiting SREBP1 expression via the Sirt1-FOXO1 pathway (Wang et al. 2009).

YGS also promoted the gene expression (Fig. 6) and transcriptional activity (Fig. 5) of FoxO. Nakae et al. (2003) reported that overexpression of FoxO1 suppressed early adipocyte differentiation. However, we found that FoxO1 is essential for the promotion of adipocyte differentiation (Munekata and Sakamoto 2009), and, therefore, the physiological role of FoxO in adipocyte differentiation remains unclear. In the current study, YGS promoted the transcriptional activity of FoxO and increased the gene expression of FoxO, SOD, and catalase, suggesting that YGS affects lipid metabolism in adipocytes partly through the action of FoxO.

Most Chinese herbal medicines have stronger effects when applied for longer periods. Our results suggest that YGS controls the expression of multiple genes through the regulation of several transcription factors, leading to the maintenance of homeostasis. Further systematic analysis of Chinese herbal medicines and gene expression may facilitate mechanistic studies and the development of clinical applications.

\section{Acknowledgments}

We wish to thank Tsumura Co., Ltd. (Tokyo, Japan) for providing Chinese herbal medicine compound. We also thank Mr. K. Tsuchiya and Ms. A. Hiraishi (University of Tsukuba) for constructing stable cell lines which carry luciferase reporter plasmids.

\section{References}

Ahtoniemi, T., Jaronen, M., Keksa-Goldsteine, V., Goldsteins, G. \& Koistinaho, J. (2008) Mutant SOD1 from spinal cord of G93A rats is destabilized and binds to inner mitochondrial membrane. Neurobiol. Dis., 32, 479-485.

Arumugam, R., Horowitz, E., Lu, D., Collier, J.J., Ronnebaum, S., Fleenor, D. \& Freemark, M. (2008) The interplay of prolactin and the glucocorticoids in the regulation of beta-cell gene expression, fatty acid oxidation, and glucose-stimulated insulin secretion: implications for carbohydrate metabolism in pregnancy. Endocrinology, 149, 5401-5414.
Barros, R.P., Morani, A., Moriscot, A. \& Machado, U.F. (2008) Insulin resistance of pregnancy involves estrogen-induced repression of muscle GLUT4. Mol. Cell Endocrinol., 295, 24-31.

Bonzón-Kulichenko, E., Schwudke, D., Gallardo, N., Moltó, E., Fernández-Agulló, T., Shevchenko, A. \& Andrés, A. (2009) Central leptin regulates total ceramide content and sterol regulatory element binding protein-1C proteolytic maturation in rat white adipose tissue. Endocrinology, 150, 169-178.

Chomczynski, P. \& Sacchi, N. (1987) Single-step method of RNA isolation by acid guanidinium thiocyanate-phenol-chloroform extraction. Anal. Biochem., 162:156-159.

Curtis, C., Landis, G.N., Folk, D., Wehr, N.B., Hoe, N., Waskar, M., Abdueva, D., Skvortsov, D., Ford, D., Luu, A., Badrinath, A., Levine, R.L., Bradley, T.J., Tavaré, S. \& Tower, J. (2007) Transcriptional profiling of MnSOD-mediated lifespan extension in Drosophila reveals a species-general network of aging and metabolic genes. Genome Biol., 8, R262.

Drevon, C.A. (2005) Fatty acids and expression of adipokines. Biochim. Biophys. Acta, 1740, 287-292.

Eckardt, K., Sell, H. \& Eckel, J. (2008) Novel aspects of adipocyte-induced skeletal muscle insulin resistance. Arch. Physiol. Biochem., 114, 287-298.

Egashira, N., Iwasaki, K., Ishibashi, A., Hayakawa, K., Okuno, R., Abe, M., Uchida, N., Mishima, K., Takasaki, K., Nishimura, R., Oishi, R. \& Fujiwara, M. (2008) Repeated administration of Yokukansan inhibits DOI-induced head-twitch response and decreases expression of 5-hydroxytryptamine (5-HT) 2A receptors in the prefrontal cortex. Prog. Neuropsychopharmacol. Biol. Psychiatry., 32, 1516-1520.

Eberlé, D., Hegarty, B., Bossard, P., Ferré, P. \& Foufelle, F. (2004) SREBP transcription factors: master regulators of lipid homeostasis. Biochimie., 86, 839-848.

Erol, A. (2009) Unraveling the Molecular Mechanisms Behind the Metabolic Basis of Sporadic Alzheimer's Disease. J. Alzheimers Dis., 16, 267-276.

Escribano, L., Simón, A.M., Pérez-Mediavilla, A., SalazarColocho, P., Del Río, J. \& Frechilla, D. (2009) Rosiglitazone reverses memory decline and hippocampal glucocorticoid receptor down-regulation in an Alzheimer's disease mouse model. Biochem. Biophys. Res. Commun., 379, 406-410.

Frescas, D., Valenti, L. \& Accili, D. (2005) Nuclear trapping of the forkhead transcription factor FoxO1 via Sirt-dependent deacetylation promotes expression of glucogenetic genes. J. Biol. Chem., 280, 20589-20595.

Fujiwara, H., Iwasaki, K., Furukawa, K., Seki, T., He, M., Maruyama, M., Tomita, N., Kudo, Y., Higuchi, M., Saido, T.C., Maeda, S., Takashima, A., Hara, M., Ohizumi, Y. \& Arai, H. (2006) Uncaria rhynchophylla, a Chinese medicinal herb, has potent antiaggregation effects on Alzheimer's beta-amyloid proteins. J. Neurosci. Res., 84, 427-433.

Hickman, S.E., Allison, E.K. \& El, Khoury, J. (2008) Microglial dysfunction and defective beta-amyloid clearance pathways in aging Alzheimer's disease mice. J. Neurosci., 28, 8354-8360.

Hong, J.H. \& Lee, I.S. (2009) Effects of Artemisia capillaris ethyl acetate fraction on oxidative stress and antioxidant enzyme in high-fat diet induced obese mice. Chem. Biol. Interact., 179, 88-93.

Iwasaki, K., Kato, S., Monma, Y., Niu, K., Ohrui, T., Okitsu, R., Higuchi, S., Ozaki, S., Kaneko, N., Seki, T., Nakayama, K., Furukawa, K., Fujii, M. \& Arai, H. (2007) A pilot study of banxia houpu tang, a traditional Chinese medicine, for reducing pneumonia risk in older adults with dementia. J. Am. Geriatr. Soc., 55, 2035-2040.

Iwasaki, K., Kobayashi, S., Chimura, Y., Taguchi, M., Inoue, K., Cho, S., Akiba, T., Arai, H., Cyong, J.C. \& Sasaki, H. (2004) A randomized, double-blind, placebo-controlled clinical trial of the Chinese herbal medicine "ba wei di huang wan" in the treatment of dementia. J. Am. Geriatr. Soc., 52, 1518-1521. 
Iwasaki, K., Satoh-Nakagawa, T., Maruyama, M., Monma, Y., Nemoto, M., Tomita, N., Tanji, H., Fujiwara, H., Seki, T., Fujii, M., Arai, H. \& Sasaki, H. (2005) A randomized, observer-blind, controlled trial of the traditional Chinese medicine Yi-Gan San for improvement of behavioral and psychological symptoms and activities of daily living in dementia patients. $J$. Clin. Psychiatry., 66, 248-252.

Kakuma, T., Wang, Z.W., Pan, W., Unger, R.H. \& Zhou, Y.T. (2000) Role of leptin in peroxisome proliferator-activated receptor gamma coactivator-1 expression. Endocrinology, 141, 4576-4582.

Kamada, Y., Takehara, T. \& Hayashi, N. (2008) Adipocytokines and liver disease. J. Gastroenterol., 43, 811-822.

Kamon, M., Fujita, D., Goto, N., Amano, H. \& Sakamoto, K. (2008) Prostaglandin F (2alpha) negatively regulates bone resorption in murine osteoclast development. Prostaglandins Other Lipid Mediat., 87, 26-33.

Kelicen, P. \& Nordberg, A. (2006) Feedback regulation of SREBP and aromatase in A beta (25-35)-supplemented human neuroblastoma cells. Cell Mol. Neurobiol., 26, 225-235.

Kivipelto, M., Ngandu, T., Fratiglioni, L., Viitanen, M., Kåreholt, I., Winblad, B., Helkala, E.L., Tuomilehto, J., Soininen, H. \& Nissinen, A. (2005) Obesity and vascular risk factors at midlife and the risk of dementia and Alzheimer disease. Arch. Neurol., 62, 1556-1560.

Kohjima, M., Enjoji, M., Higuchi, N., Kato, M., Kotoh, K., Yoshimoto, T., Fujino, T., Yada, M., Yada, R., Harada, N., Takayanagi, R. \& Nakamuta, M. (2007) Re-evaluation of fatty acid metabolism-related gene expression in nonalcoholic fatty liver disease. Int. J. Mol. Med., 20, 351-358.

Kotzka, J. \& Müller-Wieland, D. (2004) Sterol regulatory elementbinding protein (SREBP)-1: gene regulatory target for insulin resistance? Expert. Opin. Ther. Targets., 8, 141-149.

Kops, G.J., Dansen, T.B., Polderman, P.E., Saarloos, I., Wirtz, K.W., Coffer, P.J., Huang, T.T., Bos, J.L., Medema, R.H. \& Burgering, B.M. (2002) Forkhead transcription factor FOXO3a protects quiescent cells from oxidative stress. Nature, 419, 316-321.

Linseman, D.A. (2008) Targeting Oxidative Stress for Neuroprotection. Antioxid. Redox. Signal., 20, 421-424.

Liu, J.X., Liu, J., Li, P.Q., Xie, X.D., Guo, Q., Tian, L.M., Ma, X.Q., Zhang, J.P., Liu, J. \& Gao, J.Y. (2008) Association of sterol regulatory element-binding protein-1c gene polymorphism with type 2 diabetes mellitus, insulin resistance and blood lipid levels in Chinese population. Diabetes. Res. Clin. Pract., 82, 42-47.

Luchsinger, J.A. \& Mayeux, R. (2007) Adiposity and Alzheimer's disease. Curr. Alzheimer. Res., 4, 127-134.

Mahakunakorn, P., Tohda, M., Murakami, Y., Watanabe, H. \& Matsumoto, K. (2005) Effects of Choto-san and Its Related Constituents on Endogenous Antioxidant Systems. Biological. Pharmaceutical bulletin., 28, 53-57.

Matsumoto, T., Moriya, M., Kiyohara, H., Tabuchi, Y. \& Yamada, H. (2007) Hochuekkito, a Kampo (traditional Japanese herbal) Medicine, Enhances Mucosal IgA Antibody Response in Mice Immunized with Antigen-entrapped Biodegradable Microparticles. Evid. Based Complement. Alternat. Med., 29, 1-9.

Mecocci, P., Polidori, M.C., Cherubini, A., Ingegni, T., Mattioli, P., Catani, M., Rinaldi, P., Cecchetti, R., Stahl, W., Senin, U. \& Beal, MF. (2002) Lymphocyte oxidative DNA damage and plasma antioxidants in Alzheimer disease. Arch. Neurol., 59, 794-798.

Migrenne, S., Lacombe, A., Lefevre, A.L., Pruniaux, M.P., Guillot, E., Galzin, A.M. \& Magnan, C. (2009) Adiponectin is required to mediate rimonabant-induced improvement of insulin sensitivity but not body weight loss in diet-induced obese mice. Am. J. Physiol. Regul. Integr. Comp. Physiol., 296, R929-935.

Minet-Ringuet, J., Even, P.C., Lacroix, M., Tomé, D. \& de,
Beaurepaire, R. (2006) A model for antipsychotic-induced obesity in the male rat. Psychopharmacology, 187, 447-454.

Miyaoka, T., Furuya, M., Yasuda, H., Hayashia, M., Inagaki, T. \& Horiguchi, J. (2008) Yi-gan san for the treatment of borderline personality disorder: an open-label study. Prog. Neuropsychopharmacol Biol. Psychiatry., 32, 150-154.

Mizukami, K., Asada, T., Kinoshita, T., Tanaka, K., Sonohara, K., Nakai, R., Yamaguchi, K., Hanyu, H., Kanaya, K., Takao, T., Okada, M., Kudo, S., Kotoku, H., Iwakiri, M., Kurita, H., Miyamura, T., Kawasaki, Y., Omori, K., Shiozaki, K., Odawara, T., Suzuki, T., Yamada, S., Nakamura, Y. \& Toba, K. (2008) A randomized cross-over study of a traditional Japanese medicine (kampo), yokukansan, in the treatment of the behavioural and psychological symptoms of dementia. Int. J. Neuropsychopharmacol, 12, 191-199.

Munekata, K. \& Sakamoto, K. (2009) Forkhead transcription factor Foxo1 is essential for adipocyte differentiation. In Vitro Cell Dev. Biol. Anim., in press

Nakae, J., Kitamura, T., Kitamura, Y., Biggs, W.H. $3^{\text {rd }}$., Arden, K.C. \& Accili, D. (2003) The forkhead transcription factor Foxo1 regulates adipocyte differentiation. Dev. Cell, 4, 119-129.

Nasrallah, H. (2003) A review of the effect of atypical antipsychotics on weight. Psychoneuroendocrinology, 28, 83-96.

Nunomura, A., Perry, G., Aliev, G., Hirai, K., Takeda, A., Balraj, E.K., Jones, P.K., Ghanbari, H., Wataya, T., Shimohama, S., Chiba, S., Atwood, C.S., Petersen, R.B. \& Smith, M.A. (2001) Oxidative damage is the earliest event in Alzheimer disease. $J$. Neuropathol. Exp. Neurol., 60, 759-767.

Obregon, M.J. (2008) Thyroid hormone and adipocyte differentiation. Thyroid., 18, 185-195.

Olmos, Y., Valle, I., Borniquel, S., Tierrez, A., Soria, E., Lamas, S. \& Monsalve, M. (2009) Mutual dependence of Foxo3a and PGC-1alpha in the induction of oxidative stress genes. J. Biol. Chem., 284, 14476-14484.

Ott, A., Stolk, R.P., van, Harskamp, F., Pols, H.A., Hofman, A. \& Breteler, M.M. (1999) Diabetes mellitus and the risk of dementia: The Rotterdam Study. Neurology, 53, 1937-1942.

Potenza, M.A., Gagliardi, S., Nacci, C., Carratu', M.R. \& Montagnani, M. (2009) Endothelial dysfunction in diabetes: from mechanisms to therapeutic targets. Curr. Med. Chem., 16, 94-112.

Rasouli, N. \& Kern, P.A. (2008) Adipocytokines and the metabolic complications of obesity. J. Clin. Endocrinol. Metab., 93, S64-73.

Sekiya, M., Hiraishi, A., Touyama, M. \& Sakamoto, K. (2008) Oxidative stress induced lipid accumulation via SREBP1c activation in HepG2 cells. Biochem. Biophys. Res. Commun., 375, 602-607.

Sensi, S.L., Rapposelli, I.G., Frazzini, V. \& Mascetra, N. (2008) Altered oxidant-mediated intraneuronal zinc mobilization in a triple transgenic mouse model of Alzheimer's disease. Exp. Gerontol., 43, 488-492.

Shah, A., Mehta, N. \& Reilly, M.P. (2008) Adipose inflammation, insulin resistance, and cardiovascular disease. J. Parenter. Enteral. Nutr., 32, 638-644.

Shimano, H. (2002) Sterol regulatory element-binding protein family as global regulators of lipid synthetic genes in energy metabolism. Vitam. Horm., 65, 167-194.

Takeda, H., Sadakane, C., Hattori, T., Katsurada, T., Ohkawara, T., Nagai, K. \& Asaka, M. (2008) Rikkunshito, an herbal medicine, suppresses cisplatin-induced anorexia in rats via 5-HT2 receptor antagonism. Gastroenterology, 134, 20042013.

Tateno, M., Ukai, W., Ono, T., Saito, S., Hashimoto, E. \& Saito, T. (2008) Neuroprotective effects of Yi-Gan San against beta amyloid-induced cytotoxicity on rat cortical neurons. Prog. Neuropsychopharmacol. Biol. Psychiatry., 32, 1704-1707.

Tjokroprawiro, A. (2006) New approach in the treatment of T2DM and metabolic syndrome (focus on a novel insulin sensitizer). 
Acta. Med. Indones., 38, 160-166.

Tothova, Z., Kollipara, R., Huntly, B.J., Lee, B.H., Castrillon, D.H., Cullen, D.E., McDowell, E.P., Lazo-Kallanian, S., Williams, I.R., Sears, C., Armstrong, S.A., Passegué, E., DePinho, R.A. \& Gilliland, D.G. (2007) FoxOs are critical mediators of hematopoietic stem cell resistance to physiologic oxidative stress. Cell, 128, 325-339.

Wang, G.L., Fu, Y.C., Xu, W.C., Feng, Y.Q., Fang, S.R. \& Zhou, X.H. (2009) Resveratrol inhibits the expression of SREBP1 in cell model of steatosis via Sirt1-FOXO1 signaling pathway. Biochem. Biophys. Res. Commun., 380, 644-649.

Wang, P.S., Schneeweiss, S., Avorn, J., Mogun, H., Fischer, M.A., Solomon, D.H. \& Brookhart, M.A. (2005) Risk of death in elderly users of conventional vs. atypical antipsychotic medications. N. Engl. J. Med., 353, 2335-2341.
Wozniak, S.E., Gee, L.L., Wachtel, M.S. \& Frezza, E.E. (2009) Adipose Tissue: The New Endocrine Organ? A Review Article. Dig. Dis. Sci., 54, 1847-1856.

Yang, L.H., Chen, T.M., Yu, S.T. \& Chen, Y.H. (2007) Olanzapine induces SREBP-1-related adipogenesis in 3T3-L1 cells. Pharmacol. Res., 56, 202-208.

Yatin, S.M., Varadarajan, S., Link, C.D. \& Butterfield, D.A. (1999) In vitro and in vivo oxidative stress associated with Alzheimer's amyloid beta-peptide (1-42). Neurobiol. Aging., 20, 325-330.

Zhang, L., Wu, Y., Jia, Z., Zhang, Y., Shen, H.Y. \& Wang, X.L. (2008) Protective effects of a compound herbal extract (Tong Xin Luo) on free fatty acid induced endothelial injury: implications of antioxidant system. BMC Complement. Altern. Med., 14, 8 . 